\title{
Stakeholder Theory: Implications for Total Quality Management in Higher Education
}

\author{
Louis Hickman, $\mathrm{PhD}$ \\ Email: 1chickma@purdue.edu \\ Mesut Akdere, $\mathrm{PhD}$ \\ Email: makdere@purdue.edu
}

Department of Technology Leadership \& Innovation, Purdue University

\begin{abstract}
Purpose: Stakeholder theory (ST) is a reconceptualization of the firm that seeks to change business culture from being focused solely on profit and loss to being focused on creating value for the various stakeholders that are affected by or can affect the firm. Total Quality Management (TQM) is a philosophy that focuses the firm on satisfying the customer by improving organizational processes to improve quality of products and services while meeting predetermined standards. Nearly a third of U.S. voters believe colleges and universities have a negative effect on the nation, demonstrating that current quality efforts are failing in higher education (HE). This paper explores how ST can inform the practice of TQM in HE in the U.S. context.

Methodology: This paper conceptually examines ST and TQM to determine how modern TQM practice in $\mathrm{HE}$ can be informed by ST.

Findings: A reconceptualization of TQM that is informed by ST moves the focus of HE institutions' quality efforts from being narrow and internal process-focused to a more holistic and systems-oriented approach. This systems-oriented approach requires input on educational design and delivery from faculty, staff, parents, students, potential employers, the government, the community, and beyond. Traditional TQM includes a customer focus. This paper argues that TQM in HE context should have a stakeholder, rather than customer, focus by challenging TQM philosophy to widen its scope of customer to a whole new level.

Value: By extending the parties considered when designing education beyond students and industry, HE institutions can ensure that the various HE stakeholders and society at large may benefit from their continued operation. Bringing together diverse viewpoints and perspectives when considering changes to institutional structures, policies, and programs will ensure that no stakeholders are left behind as we design our institutions for success in the emerging $21^{\text {st }}$ century.
\end{abstract}

Keywords: Stakeholder Theory, Total Quality Management, higher education, stakeholders, quality

Paper Type: Conference 


\section{Introduction}

A recent poll by Pew Research Center showed that 30\% of Americans believe our HE institutions are negatively impacting the U.S. (Pew Research Center, 2016). The opinion was deeply divided along partisan lines, suggesting that HE is failing to address the needs of certain stakeholders. TQM has been widely adopted throughout HE, whether in its original form or as new methodologies like six-sigma, which involve all the required features of TQM (Green, 2006). TQM focuses on improving quality for the customer. The student is commonly considered the customer in HE context. While some colleges fail to even make the students' satisfaction paramount (Levine, 2005), failing to account for the wider societal stakeholders represents a shortcoming. ST argues that to succeed, firms must concern themselves with "any group or individual who can affect, or is affected by, the achievement of a corporation's purpose" (Freeman, 1984, p. 53). If HE institutions focus only on satisfaction of students and/or their potential employers, they are failing to account for most of their stakeholders.

This paper argues that, rather than solely focusing on customer satisfaction as targeted by TQM, HE institutions should expand the focus of quality efforts to all stakeholders. Ensuring that the various stakeholders are both satisfied and receiving positive value should further improve the public opinion and societal-level outcomes of HE. Focusing on stakeholders rather than customers would remove one of the major barriers to implementing TQM in HE, which is the difficulties experienced in identifying who the customer is. The remainder of the paper first provides an overview of ST then discusses the implications of ST for TQM efforts in HE.

\subsection{Stakeholder Theory}

ST suggests that stakeholders be treated as an end in and of themselves rather than as means to creating profit. The ST conception of the firm, then, is especially relevant for non-profit settings such as HE. A stakeholder-oriented organization creates value for all of the organization's stakeholders. Organizations which "have purpose and values beyond profit maximization" (Freeman et al., 2010, p. 12) tend to be high performers. Creating value for stakeholders, then, improves organizational well-being. Providing value to an organization's stakeholders necessitates not only recognizing who the stakeholders are but also understanding their perceived stakes, the processes being used (both explicitly and implicitly) to manage stakeholder relationships, and if those processes are resulting in transactions and bargains that fit the processes and strategic plans laid out by the organization (Freeman, 1984).

Understanding stakeholder needs is best accomplished through voluntarism, a term Freeman (1984) uses which means, simply, voluntary negotiation. Voluntarism enables discovery of winwin solutions where value is created without resorting to tradeoffs. No tradeoffs, for Freeman, means that we should strive in every situation to prevent stakeholders from being harmed or receiving negative value. Additionally, voluntarism prevents "from having a solution imposed on the organization from outside" (1984, p. 77), such as occurred at the University of Missouri in 2015. Extensive voluntarism should make university behavior more proactive, rather than reactive (Post et al., 2002).

This focus on proactivity resulted in Freeman (1984) suggesting that internal stakeholders should only be included as conduits through which we affect external stakeholders. University changes that impact employees (whether staff or faculty), then, would be most effective when those 
changes impact external stakeholders, such as students, employers, and society. A recent example at a Midwestern university saw a vice president decide to purchase a product that required faculty to enter their curriculum vitae online. No prior discussions were made with faculty and no resources were provided to faculty to help them with this laborious process of integrating the tool as part of their academic work. Approximately one year after the product was implemented, it was defunct. The project was intended to make it easier to identify faculty who were deserving of awards - an outcome which may have eventually affected rankings on the U.S. News and World Report but does not impact any external stakeholders. Stakeholder expectations change year to year, so it is vitally important to communicate with them because socalled stakeholder "experts" are commonly wrong (Freeman et al., 2010).

Genuine attempts to communicate and understand stakeholders should result in increased trust and sense of fairness (Harrison et al., 2010). Only by establishing trust will stakeholders freely provide useful information, since they would believe that doing so would improve their position. Effective relationships with stakeholder groups can be a source of competitive advantage if the behaviors driving the relationships become embedded in organizational culture. Competitive advantage stems from having positive relationships with external stakeholders, which makes a firm more systems-oriented rather than internal process-oriented. Focusing on value creation for stakeholders rather than solely on customers will create win-win situations that would present benefits beyond customer satisfaction.

\section{Implications of Stakeholder Theory for Total Quality Management}

As a result of TQM's focus on total customer satisfaction, a significant amount of HE research on quality has had to debate over who should be considered the customer (Quinn et al., 2009). Particularly concerning is that researchers cannot decide whether students are customers or raw material. Taking a faculty perspective, some researchers consider students as raw material that is developed for future employers and society, who are the customers. Other researchers consider students to be the customer since they are consuming the educational 'product', while still others have pointed out that students act a lot like employees (Helms \& Key, 1994). Considering that TQM implementations in industry are prone to failure when they do not include the voice of the customer (Brigham, 1993), the lack of clarity of HE's customer is an additional hurdle. Lawrence and Robert (1997) suggested that TQM is inappropriate for HE because it is impossible to identify an appropriate customer. Adopting the perspective of ST, this debate would be null. Rather than identifying a single customer, we can identify all these groups and more as stakeholders and ensure that improvement efforts benefit multiple stakeholders. The process is difficult. Even within TQM, soliciting customer feedback and input in organizations unaccustomed to doing so is a daunting task (Brigham, 1993). Therefore, including the voice of stakeholders is an even larger project that will take serious time, effort, and reinforcement to achieve.

Venkatraman (2007) laid out a framework for implementing TQM in HE. He suggests that "the core educational business process" is both student learning and teaching because it is "the main vehicle for achieving customer satisfaction and quality improvements" (p. 102). To identify who the customer is for HE, Venkatraman adopts the term stakeholder. He claims that customers are "more appropriately referred [to] as stakeholders in education" (2007, p. 99) without providing any further explanation. He states that students are the primary external customers, employers 
and parents are secondary external customers, with government, the labor market, and alumni as tertiary external. He includes faculty as internal customers. He provides no justification for why all these stakeholders should be included, but we argue that even this listing of stakeholders is short. This list does not include society, the local community, suppliers, and other important stakeholders. Not only must we concern ourselves with each stakeholder group, but we must recognize that stakeholder groups are not homogeneous. A majority of students, at the University of Missouri for example, did not have a protest-worthy problem, but a minority felt their voice was not being heard. Recognizing the varied segments within stakeholder groups is important to prevent solutions being imposed from the outside (Freeman, 1984). ST provides justification for including stakeholders as the focus of improvements made under TQM.

Venkatraman's (2007) framework has a major shortcoming, however, when he details the customer focus. The only customers he includes are students and industry. This is surprising considering he points out both the importance of customer voice and consideration of a variety of stakeholders as customers. His entire description of framework implementation focuses on process and collecting feedback only from students. In other words, the implementation is internal and process-oriented whereas ST purports a more holistic and process-orientation. This paper argues that inclusion of ST as a part of TQM process in the HE context would resolve such shortcomings, because while it is easy to argue in the justification of a framework that stakeholders should be the customer in HE context, ensuring that level of inclusiveness in the definition and implementation of a framework is much more difficult. Much business and HE research refers to stakeholders without referring to ST. Incorporating ST in TQM will provide a normative basis that supports HE efforts to provide value to a varied set of stakeholders.

\section{Conclusion}

HE has faced increasing pressure to reach a diverse group of stakeholders as our political discourse has become more polarized. Nearly one-third of Americans believe universities are harming the country. Our HE institutions must ensure they are providing value to a broader group of stakeholders, and future research should examine the extent to which doing so improves perceptions of universities both individually and collectively. Much of the focus in HE in recent years has not been on satisfying a diverse group of stakeholders but, rather, on improving a select few metrics considered important by a small number of university power ranking lists. These metrics are a red herring. They do not necessarily represent better value provided to students, and they were not important until the rankings existed and become valued (O'Neil, 2016). Gaining greater stakeholder voice and inclusion in improvement processes will help to ensure that the improvements focused on in our HE institutions provide real value for our students, faculty, communities, and society.

\section{References}

Brigham, S.E. (1993), TQM lessons we can learn from industry, Change, Vol.25, No.3, pp. 3136.

Green, F.B. (2006), Six-Sigma and the revival of TQM, Total Quality Management, Vol.17, No.10, pp. 1281-1286.

Freeman, R.E. (1984), Strategic Management: A Stakeholder Approach, Pitman: Boston, MA. 
Freeman, R.E., Harrison, J., Wicks, A., Parmar, B., \& de Colle, S. (2010), Stakeholder Theory: The State of the Art, Cambridge University Press.

Harrison, J.S., Bosse, D.A., \& Phillips, R.A. (2010), Managing for stakeholders, stakeholder utility functions, and competitive advantage Strategic Management Journal, Vol.31, No.1, pp. 58-74. doi: $10.1002 / \mathrm{smj}$

Helms, S. \& Key, C.H. (1994), Are students more than customers in the classroom? Quality Progress, Vol.27, No.1, pp. 97-99.

Lawrence, R.J. \& Robert, A.O. (1997), A violation of assumptions: Why TQM won't work in the ivory tower, Journal of Quality Management, Vol.2, No.2, pp. 279-291.

O’Neil, C. (2016), Weapons of Math Destruction: How Big Data Increases Inequality and Threatens Democracy, Crown: New York.

Pew Research Center. (2016), From universities to churches, Republicans and Democrats differ in views of major institutions. Retrieved from http://www.pewresearch.org/facttank/2016/09/26/from-universities-to-churches-republicans-and-democrats-differ-in-views-ofmajor-institutions/

Post, J.E., Preston, L.E., \& Sachs, S. (2002), Redefining the corporation: Stakeholder management and organizational wealth, Stanford University Press: Stanford, CA.

Quinn, A., Lemay, G., Larson, P., \& Johnson, D.M. (2009), Service quality in higher education, Total Quality Management \& Business Excellence, Vol.20, No.2, pp. 139-152. doi: $10.1080 / 14783360802622805$

Venkatraman, S. (2007), A framework for implementing TQM in higher education programs, Quality Assurance Education, Vol.15, No.1, pp. 92-112. 